\title{
The grammar of visual design
}

\author{
Susan Roberts and Robyn Philip \\ Macquarie University
}

\begin{abstract}
The ability to interpret information from any source, and increasingly visual sources, is a vital skill for all graduates in contemporary culture. The development of the skills to read visual texts and communicate that understanding requires a certain level of critical thinking and reflection, skills which can only be developed over time, through practice and dialogue. This paper reflects on the evaluation of two websites. These resources support students in two units of study which aim, amongst other things, to develop visual literacy and critical thinking skills using the functional systemic concepts developed by Kress and van Leeuwen (1990, 1996). The challenge for the authors was to create two online resources for distance students that exemplified the theory itself and scaffolded learning as students developed their own level of skills in this area.
\end{abstract}

\section{Introduction}

Contemporary culture is marked by important developments in the way we communicate. Most of us now access information from the web or other new digital media sources virtually every day. These media carry messages equally through image, or through an integrated composition of print and image. In addition, changes in ICTs have meant that images are now increasingly incorporated into the majority of most types of texts (Kress, 1997; Healy, 2000; New London Group, 2000). Reading such messages and texts requires both verbal and visual literacy, and the ability to read the interaction between both verbal and visual elements. Without these literacy skills, it is difficult to see how we could survive in the contemporary world.

It is not surprising that visual literacy is now part of the curriculum at every level - preschool through to tertiary level. Educationalists recognise that students need to be competent in interpreting texts of all kinds. For example, the NSW Board of Studies considers 'viewing' as a part of literacy development and describes visual literacy as a learning outcome, defined as 'observing and comprehending a visual text such as a diagram, illustration or photograph' (English K-6 Modules, 1998, p.100). We would 
add computer and video screens to that list. Competence in using information and communication technologies, which require visual literacy, is also a common graduate outcome at the tertiary level.

It is also essential that we understand visual language in order to be critically literate. Jewett and Oyama (2001) have shown how important health messages may visually encode narrow constructions of gender. Kress and van Leeuwen (1996, p. 254) have shown how children's toys may steer very young children to gendered play. In both cases, the readings were based on a systematic approach to articulating visual meaning.

Unfortunately, there are few agreed methods for articulating the way images and composite texts are read (Anstey \& Bull, 2000; Unsworth, 2004). This is unlike the case for verbal texts where we have several agreed ways of articulating verbal meaning. This is a problem for teachers as without an agreed method for articulating visual meaning, it is difficult to assist learners to develop visual literacy skills.

Kress and van Leeuwen $(1990,1996)$ provide a useful way forward. A great advantage of their method for reading the visual is that it allows multiple readings of the same visual text. Their method for reading the visual is based on semiotic principles (how meaning is made and understood) and is widely used by academics and practitioners in the areas of functional linguistics and visual discourse analysis (for example: Callow 1999, Jewitt \& Oyama 2001). It provides detailed and explicit methods for analysing the meanings established by the syntactic relations between people, places and things depicted in images. These meanings are described as not only representational (the representation of entities, whether physical or semiotic), but also interactive (images construct the nature of relationships among viewers and what is viewed) and compositional (the distribution of information value or the relative emphasis among elements of the image).

However, the method is complex and conceptually challenging for most students. It introduces new terms and reuses old terms in quite precise ways. The authors, like academics elsewhere (for example, Veen, 2002), have recognised the need to facilitate students' learning by designing specific learning resources. We found that existing resources were of limited use for our purposes as we wanted to introduce the theory in a paced way, then exemplify its use in practice. It is self evident that visual resources embody visual meaning. We believed that it would be effective and convincing to design visual resources which implied the very concepts we wished students to explore. Kress and van Leeuwen's theory of social semiotics that applies to the visual image, also called the grammar of visual design, should therefore benefit from visual explanation and elaboration. 
In this paper, through various approaches, we aim to show how we addressed the students' need to enhance their visual and critical literacy skills. We seek to establish how well the support resources created met that need, and we reflect on improvements or further research that might be taken up in this area.

\section{Design and rationale for the learning resources}

Two websites were developed to assist students' understanding of reading images of the child using the work of Kress and van Leeuwen $(1990,1996)$. The students were enrolled in Images of Childhood (undergraduate) or Image, Text and the Child (postgraduate). The majority of these students were studying early childhood education so they were interested in both learning about, and eventually teaching, visual literacy. Tutorials (one on campus session and an online bulletin board discussion), recorded audio lectures and print resources were already used to facilitate students' learning of visual grammar. The additional web resources, built in 2000, with the limitations of the technology at that time, were expected to provide more visual examples and opportunities for practising visual analysis.

Two principles governed our choices in designing the first of these websites, Reading the Visual, one based on representational principles, the other based on learning outcomes. As a representation, we designed this site to function like a combined taxonomy and flowchart (see Figure 1). The taxonomy derived from the overarching authority of the functional model of communication as proposed originally by Michael Halliday (Halliday, 1994). This provided the single unifying schema. The flowchart structure derived from the idea that the site should progress sequentially and be goal orientated (see Figure 2 for a flow chart of the Interpersonal section of the site). The result is that the site functions as an online tutorial. It introduces the grammar of visual design in a paced fashion, presents the concepts both verbally and visually, and provides examples and opportunities to practise visual analysis, in some cases by manipulating the images, using Shockwave, within the browser interface.

As authors of the site, we adopted an educational voice in so far as we wanted the students to read the conceptual material as factual information. By adopting the abstract structures of flowchart and taxonomy, we provided a kind of knowledge about the meaning of images, but by using interesting images, we also showed that we wanted to persuade the students to engage with the material. In short, we aimed to set in motion the actual process of learning but we also addressed the students as readers whose interest needed to be won. We also used the principles of visual grammar wherever possible - top and left of screen as more user friendly 
spaces for crucial information and no large blocks of unbroken verbal text. And we did not use technology just because we could.

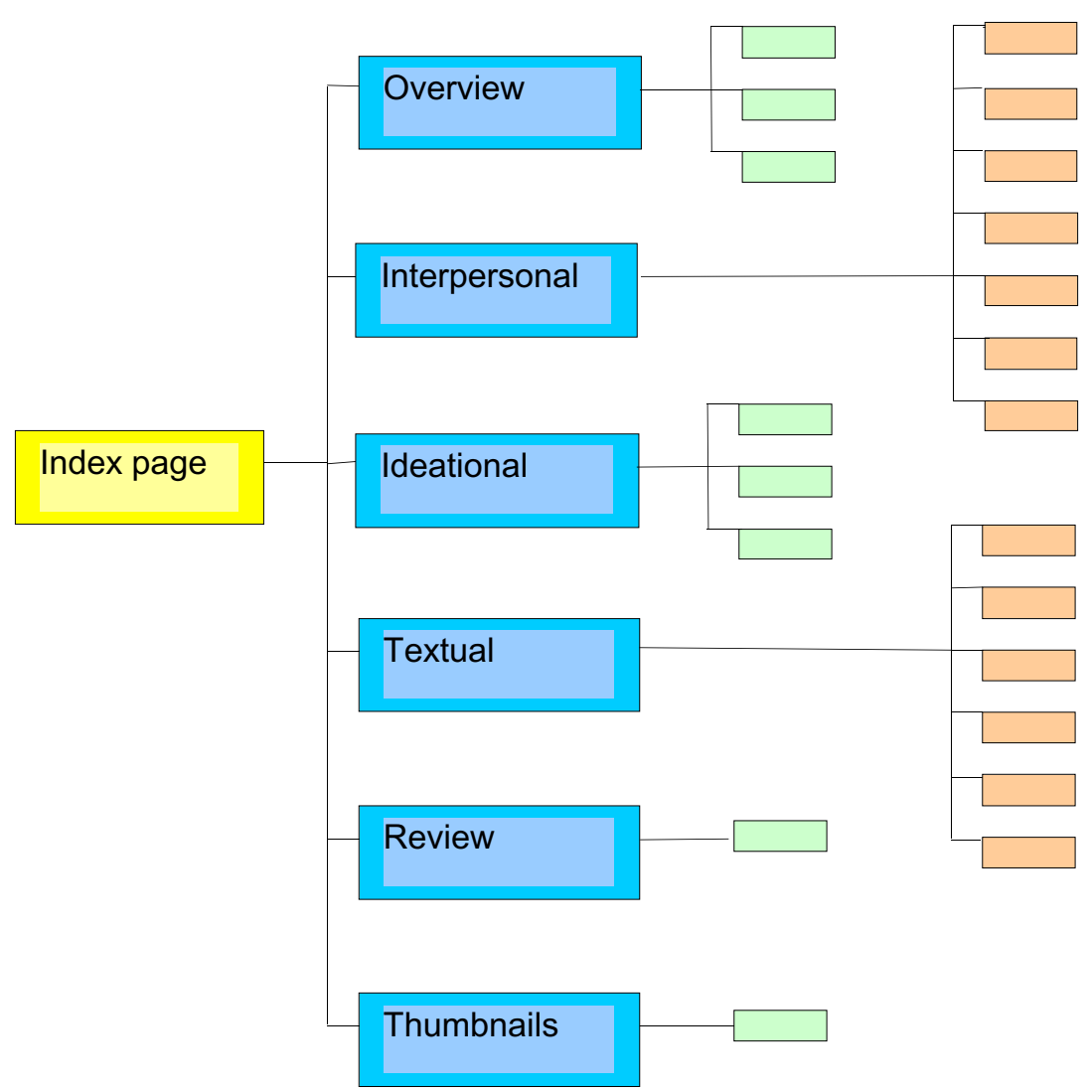

Figure 1: Overview of the structure of the tutorial Reading the Visual

As users of the site, students were expected to move in and out of small sections of the tutorial as they chose, or navigate sequentially through from section to section, depending on their familiarity with the content and preferred learning style. Students had the choice of reading in linear order from beginning to end, or stopping and returning to earlier sections, or skipping sections and so forth. They also had the choice of navigating via hyperlinked icons and words scattered throughout the site. These icons and words link to useful definitions, their purpose was of course to enhance understanding rather than distract attention, so they could be called 'supplemental' rather than 'incidental' (Unsworth, 2003). 


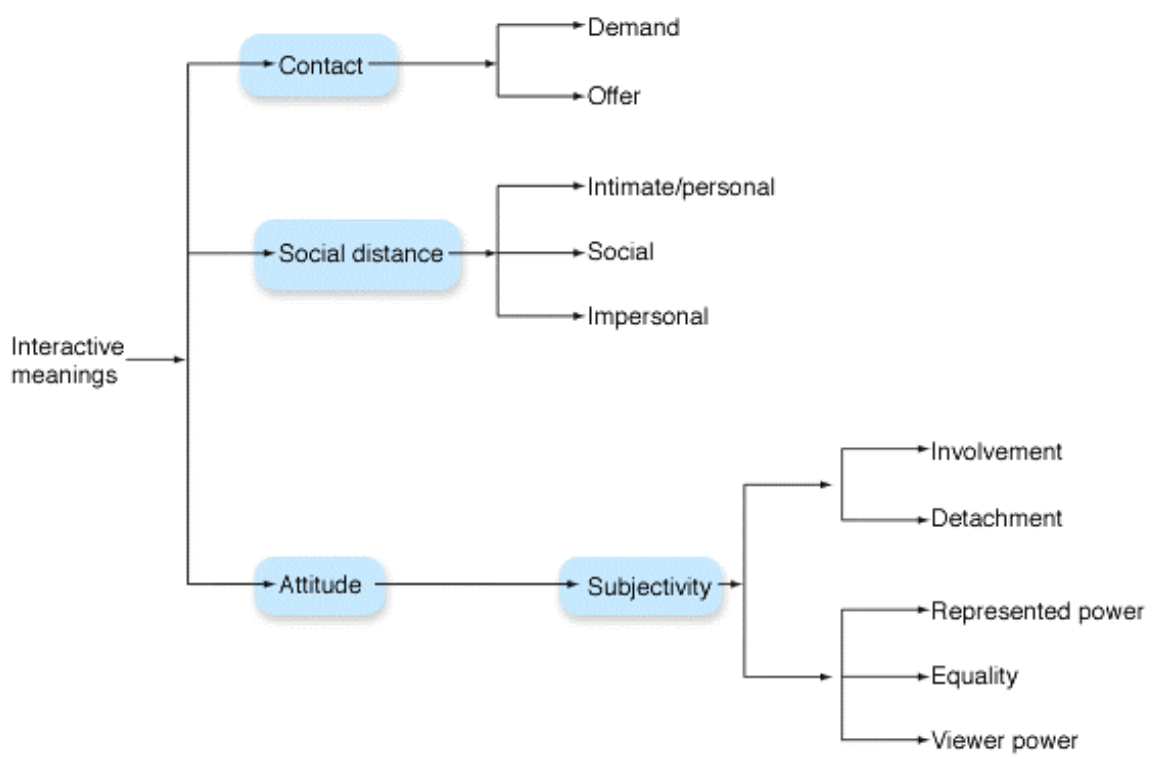

Figure 2: Navigational flow chart, showing navigation through the 'Interpersonal' section of the Reading the Visual website, derived from Kress and van Leeuwen (1996, p.154).

Giving learners this choice brings difficulties in terms of design, especially in making explicit the extent and scope of the online resource. The importance of clear structure, design and communication are well documented (for example, Hedberg, Brown \& Arrighi, 1997; Hedberg \& Harper, 1992; Sims, 1998). As Kristoff and Satran (1995, in Sims 2003, p.89) observe: 'Choice can take users in unpredictable directions and combine elements of the design in unpredictable ways. That is why interactivity calls for a greater commitment (than ever before) to planning, to usability, and to making the pieces work together'. We designed the website so that should a student become lost, it would be possible to discover where $\mathrm{s} /$ he is in the flowchart structure. Additionally the breadcrumb navigation supplied through the WebCT interface provided some additional record of their journey through the resources. We aimed to ensure the navigation was intuitive, that there was learner control of pace, that opportunities for learner reflection were maximised and, within the budget available, that students were given the opportunity to manipulate and have control over some of the visual examples.

The Family Album, http://www.lib.mq.edu.au/readingthefamilyalbum/ picman/, was designed to complement Reading the Visual as it showed 
students how we used these functional concepts of visual grammar in the practice of reading particular images. We accessed a large collection of photographs from Australian family albums from the period 1870 to 1930 (State Library of New South Wales Collections, 2000, Picman collection), selected 40, and classified them under four broad themes: the beach, the backyard, gatherings and institutions (see Figure 3: Girls at St Joseph's Orphanage classified as fitting the theme Institutions). Each photo was then analysed as far as possible using concepts derived from Kress and van Leeuwen. Some key concepts were contact, realised by gaze offered or gaze denied (because it is thought that there is a fundamental difference between pictures from which figures look directly at the viewer, and pictures in which this is not the case); social distance, embodied by the size of frame; and subjectivity, realised by such things as the angle from which the image is taken. We found that we also needed to draw on our knowledge of social theories of childhood, particularly of gendered childhood, in order to complete the analyses, as, in agreement with Jewitt and Oyama (2002, p.154), the theory 'does not, on its own, offer all that is needed for the sociological interpretation of images'.

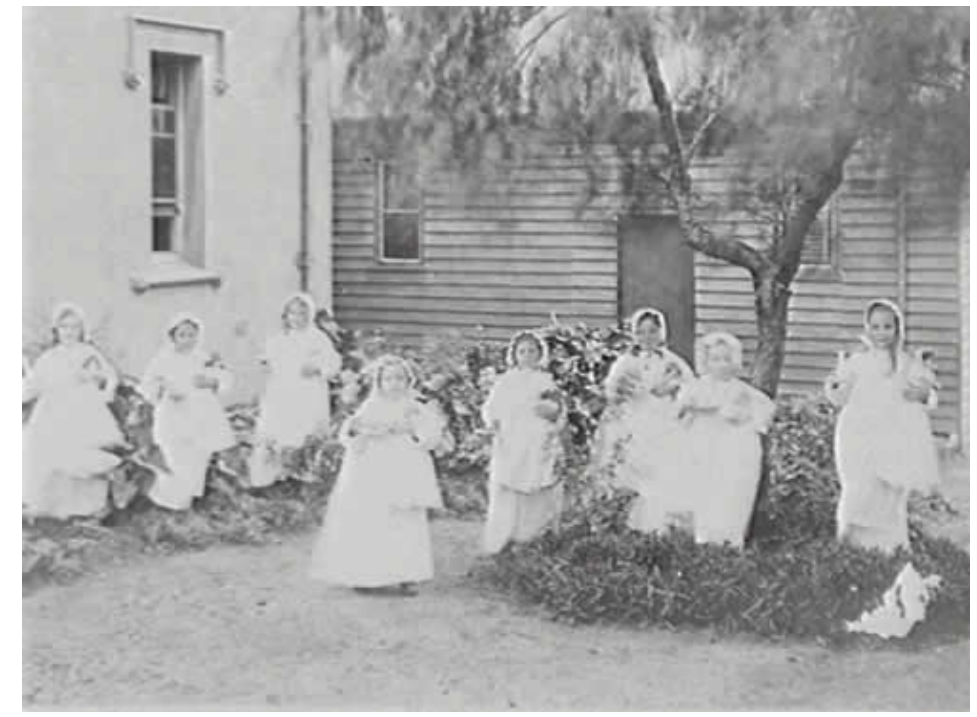

Figure 3: Girls at St Joseph's Gore Hill Orphanage, 'Institutions' section of Reading the Family Album.

(Photo used under licence from the State Library of NSW)

As a representation, this site was designed as a taxonomy, in which the proposed similarities between the images grouped under a specific theme were realised visually by a symmetrical composition. Each image was 
Reading the Family Album:

Historical Images of Australian Childhood

Introduction | Institutions | The Beach | Gatherings | The Backyard | Bibliography

Gatherings, Outings and Automobiles

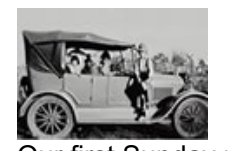

Our first Sunday picnic in the new car.

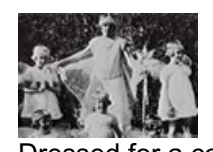

Dressed for a concert Stockinbingal.

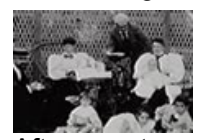

Afternoon tea - Inverell.

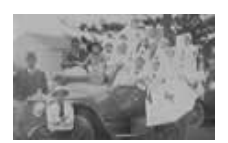

Centenary celebrations Port Macquarie.

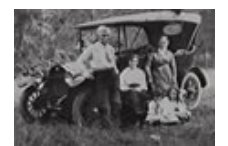

Motoring excursion Penrith area.
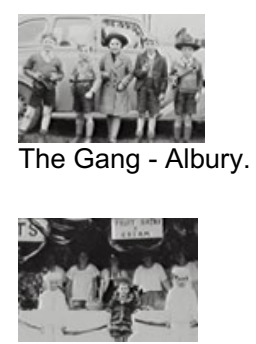

Sweet stall - Smithtown.

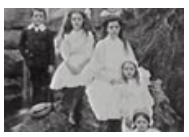

Picnic in bush - Leura.

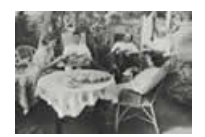

Tea at Nutwood -

Drysdale River, NT.

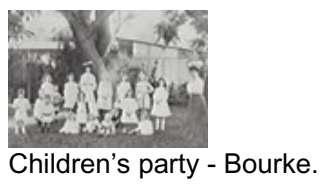

Figure 4: Structure and visual layout of Reading the Family Album.

'Gatherings' section. Analyses written by Lyn Clugston, edited by Susan Roberts.

Images used under licence from the State Library of New South Wales.

placed at equal distance from each other, given the same size and the same amount of verbal interpretation. In addition, there was an overarching symmetry imposed by choosing the same number of photos (10) to exemplify each theme. (See Figure 4.) Of course, we could have chosen different themes but whatever themes we chose, we wanted the structure 
to be signposted and symmetrical so that students could browse through the site easily, much as they might browse through a family album. We did not want to repeat the elaborate structure of Reading the Visual which entwined taxonomy with flowchart.

\section{Aims}

The general aim of the investigation was to explore the usability and interactivity of these websites for tertiary learners at both undergraduate and postgraduate levels. In terms of usability we were interested in user perceptions of the clarity of the navigation for locating information, and their views on the effectiveness of the chosen images. In terms of interactivity, we were concerned with whether students were engaging meaningfully with the resources, as indicated by their involvement with, awareness of, and access to the resources (Sims, 2003; Sims 1998). We were interested in their interaction with the resources and the Kress and van Leeuwen theory.

Specifically, this evaluation aimed to answer the following questions:

1. How effective are the two websites Reading the Visual and Reading the Family Album in fostering students' visual literacy skills and facilitating their understanding of the theoretical framework offered by Kress and van Leeuwen?

2. What modifications to the websites are necessary to improve their understanding?

\section{Methods}

In the first part of the study, data was gathered from three main sources: self reflection exercises, questionnaires, talk aloud protocols and interviews. In the second part, a focus group was conducted to gather data on the success or otherwise of the websites after they were modified, following feedback from the students.

\section{Self reflection exercise}

Fifty four undergraduate distance students, of an enrolment of sixty students, attended the on campus session. They were asked to complete a self-reflection exercise once at the beginning of the on campus session and again at the end. This exercise was based on a questionnaire given each year to students as a means of assessing their visual literacy skills and understanding, before and after engaging with visual grammar in a face to face teaching session. In the context of this study, the first set of reflections 
served as a baseline of student understanding before they had engaged with the electronic resource. The students could choose not to complete the self reflection exercise, in keeping with the ethical requirements of this study.

The students were asked to reflect on a particular image and answer five questions: Where do you look initially? What is represented? How realistic is the image? How does this image engage you? How do all the elements combine together to make a coherent visual text? These questions were derived from Callow (1999). They focus on different features of the image that can lead students to describe how an image may be constructed and the sorts of functional codes the image maker may have used.

\section{Questionnaire}

All sixty undergraduate students were invited to complete an anonymous online questionnaire designed to examine closely the role these websites played in the students' learning of visual grammar. The SurveyMaker online questionnaire tool (http://www.surveymaker.com.au/) was used to design a questionnaire which contained 19 mainly open ended style questions about the two websites, Reading the Visual and Reading the Family Album. The whole class questionnaire provided data against which to compare the views of the six students interviewed during the 'talk aloud' sessions.

\section{Talk aloud protocol and interview}

This method is useful for gaining information from users as they engage with a learning resource, verbalising their thoughts as they interact with it and talking through their reactions. The observer intervenes in the flow of thought and talks as little as possible (Bernadini, 2002; van Someren et al, 1994).

For effective user testing Nielsen (2000) recommends conducting say, three tests with five users rather than one single test with 15 users. The first test is expected to reveal the bulk of weaknesses with the resource. After the initial problems have been identified and corrected, testing with the same group of users is expected to uncover any remaining problems, and reveal any new problems created by the first round of amendments, if any. For our purposes we conducted two tests with six users. A third test was not necessary because the second test did not reveal any new problems.

Six students accepted the invitation to participate in the talk aloud sessions. They were invited to participate in the review of the sites after their relevant assessments had been submitted. Following the talk aloud session, 
each student was interviewed, and the interviews recorded. Both authors were present during the interviews, one acting as the note taker while the other interviewed the student. These students were asked questions about how familiar they were with the two sites; how comfortable they were with the technology; the best things about each site and where improvements could be made; as well as content questions which aimed to reveal their conceptual understanding.

\section{Focus group}

After the modifications were completed, the same six students were invited to a group interview, where they viewed the websites again. Each participant reviewed the resources on her own, wrote down her initial thoughts without reference to others in the group, and then discussed each response in a group with the two authors.

\section{Results}

\section{Self reflection exercise}

Thirty four students (63\% of the sample) chose to answer the questions. Over the years, we have found early childhood students to be visually intuitive and responsive to visual imagery, but lacking the specialist vocabulary and conceptual understanding to adequately express that visual meaning. This cohort was no exception.

\section{Where do you look initially?}

This question required good observational skills to answer well, but did not need specialist vocabulary. For example, students did not use the term salience to describe elements which most attracted their attention within the composition but referred to the various sub-codes of salience, such as elements with saturated or bright colour and the human face and figure.

\section{What is represented?}

Students answered the next question in terms of what was actually happening in the image, the actions and setting. They did not refer to other semiotic systems or enitities.

\section{How realistic is the image?}

They answered the third question without referring to the various modality markers which help us decide whether to read an image as naturalistic or not (eg, fairly saturated and modulated colour).

\section{How does this image engage you?}

The fourth question too was answered in a surface way, for example by referring to eye contact, but there was no reference to whether the people 
and setting in the image were close enough or oriented frontally in such a way as to involve the viewer.

5. How do all the elements combine together to make a coherent visual text?

Finally, the fifth question was poorly answered because students lacked the terminology to make meaningful observations about composition, or about the other features of the image which contribute to its cohesion.

From the above, we can infer that the students showed quite good preliminary understanding of the meaning of visual images. However, they needed to learn how better to articulate their understanding of visual meaning; hence the need for resources such as Reading the Visual and The Family Album.

\section{The questionnaire, talk aloud and interview responses}

Fifteen students responded to the survey (25\% response rate). Most students $(73 \%)$ were aged between $17-25$ years of age and there was only one male in the sample. These proportions accurately reflect the age and gender balance in the total enrolment. The majority $(67 \%)$ had not studied visual arts or media at university before, so engaging with the concepts of visual grammar was demanding for them, requiring high levels of critical thinking skills.

\section{Learning styles and methods of using the resources}

The questionnaire responses and the findings of the usability tests both indicated that the sites were quite easy to navigate. $80 \%$ of respondents rated navigation of Reading the Visual as excellent or good, and one respondent only rated it as very poor. No respondents found the Family Album's navigability below average. Interestingly students thought there was some room for improvement of Reading the Visual's navigability which we had perceived as straight forward. (See Table 1.)

Table 1: Navigation in discovering the scope of the site

\begin{tabular}{|c|c|c|c|c|}
\hline $\begin{array}{l}\text { Rate the } \\
\text { your way }\end{array}$ & & $\begin{array}{l}N \text { easy } \\
\text { tions }\end{array}$ & $\begin{array}{l}\text { s it to } 1 \\
\text { d 15) }\end{array}$ & find \\
\hline & Rea & Visual & Reading & nily Album \\
\hline & $n$ & $\%$ & n & $\%$ \\
\hline Excellent & 6 & $40.0 \%$ & 3 & $20.0 \%$ \\
\hline Good & 6 & $40.0 \%$ & 8 & $53.3 \%$ \\
\hline Average & 2 & $13.3 \%$ & 4 & $26.7 \%$ \\
\hline Poor & 0 & $0.0 \%$ & 0 & $0.0 \%$ \\
\hline Very poor & 1 & $6.7 \%$ & 0 & $0.0 \%$ \\
\hline Total & 15 & $100.0 \%$ & 15 & $100.0 \%$ \\
\hline
\end{tabular}


Table 2: Confidence in discovering the scope of the site

\begin{tabular}{|c|c|c|c|c|}
\hline \multicolumn{5}{|c|}{ How confident were you that you located all the sections of the } \\
\hline & \multicolumn{2}{|c|}{ Reading the Visual } & \multicolumn{2}{|c|}{ Reading the Family Album } \\
\hline & $\mathrm{n}$ & $\%$ & $n$ & $\%$ \\
\hline Very confident & 5 & $33.3 \%$ & 5 & $33.3 \%$ \\
\hline Confident & 9 & $60.0 \%$ & 10 & $66.7 \%$ \\
\hline Not very confident & 1 & $6.7 \%$ & 0 & $0.0 \%$ \\
\hline Total & 15 & $100.0 \%$ & 15 & $100.0 \%$ \\
\hline
\end{tabular}

From the interviews we learnt that students tended to explore the websites early in the semester, and then returned to them when the major assessment was due. According to their learning style, which can be influenced by prior experience and the learning context (Laurillard, 2002, p.28), some interviewed students worked through the resource methodically from beginning to end, while others took a fairly pragmatic approach, dipping in and out at will. It was noted on observing these 'pragmatic' students that they were more likely, however, to have missed sections of the site, such as the Overview or the Review. Interestingly, 93\% of surveyed students were confident that they had located all the sections of Reading the Visual and 100\% said they found all sections in The Family Album. We believe the flow charts of the first site and the visual symmetry of the layout of the second helped reveal the scope of the respective sites.

The questionnaires revealed that more than a third of the students studied the resources online $(37.5 \%)$, half the students studied online and printed out the resources $(50 \%)$, and a minority ( 2 of the 15 students, $12.5 \%$ ) worked mainly from printed resources. Whether some students were missing opportunities to manipulate the images online was not clear from the questionnaire responses, but the individual interviews revealed that this could have been the case. So while 14 of the 15 survey respondents (93\%) reported confidence in locating all sections of the two websites, there were still important interactive elements that may have been missed.

Both the questionnaire and the talk aloud protocol revealed a range of responses regarding the contribution each website made to an individual's understanding of visual grammar. Students who effectively engaged with the tutorial support of Reading the Visual made comments such as this:

By providing direct examples correlating with the reading and lecture tapes, meaning was made easier to understand... The website developed my understanding to a new level I could not have gained from simply reading or listening.

It was the resource I relied on most heavily as it was simple, practical, straight to the point and easy to navigate. 
On the other hand, a student who preferred more traditional learning supports said:

Minimal - relied on texts more so. Activities at on campus session contributed far more to my understanding.

The interviewed students said that they may not have understood all the concepts in the beginning, but on repeated use of both sites found the concepts became clearer. The interviews also revealed that all six students seemed to have developed a reasonable grasp of the theoretical concepts or how they could be applied.

The visual examples on the sites were chosen to be provoking and stimulating, as were the questions posed. One student said that just reading the expository material rarely gave her the sense of the relative importance of concepts ('Don't know what the emphasis is. The questions give you a sense of what is important'). Not all questions posed were answered in the Reading the Visual tutorial - a deliberate strategy to encourage student self-reflection. It was also an outcome of the fact that in some cases, the image supported more than one reading. Some students found this ambiguity challenging. One student said she found it hard to tolerate uncertainty. Another found it difficult to understand that images could support more than one reading informed by the concepts of visual grammar. Another commented, 'I found some of the interpretations to be subjective and personally didn't agree with them'. One of the student's comments from the survey shows how visual literacy skills and understanding needs to build up over time, often through the use of multiple representations of the same topic:

The very first time I explored the website it did not help me. But after reading my book and listening to the lecture tapes it put it all together for me.

\section{Engagement}

The six interviewed students expressed enjoyment of The Family Album, commenting that the photos were engaging, for example, 'It is interesting to see children from this bygone era - they were not portrayed as powerful then'. The students liked the opportunity to manipulate the images at certain points on the Reading the Visual website, for example the doll where the eyes could be moved from side to side indicating the importance of gaze; the heads of the girls which switched, indicating the importance of vectors for forming reading path; and the weight loss advertisement of two pictures of the same woman before and after weight loss, showing the role of left/right placement in the distribution of given or new information. In sum, the interviewed students indicated to us that they liked experimenting with the concepts in this playful way, demonstrating control and engagement, two important features noted by Sims $(2003$, p.93) in his 
discussion of the key characteristics of interactivity specifically in the educational sense, namely control, engagement, communication and design).

The conversational tone of the surrounding text gave an immediacy which is important for any online course where the lecturer and other students are not physically present. In relation to this, one student commented favourably on the tutorial's personal tone, 'it is as if you were talking to me'.

Three of the interviewed students commented that as distance students it was good to have more than just the audio lectures and the online materials. Two said that, as distance students, they missed out on such learning opportunities as interacting face to face with staff and other students, so appreciated resources which supplemented the materials in other ways. Also, for some students, the interpretive text accompanying the photos of the family album acted as a model for writing essays and analysing visual texts.

\section{Stage 2: Modifications to the resources}

In keeping with the second aim, we modified the sites in accordance with the findings of the usability sessions and questionnaire responses. We aimed for clarity and avoided unnecessary complexity which frustrates novice users (Northrup, 2001). The modifications were grouped into three areas: improvements to navigation (six changes), additions to better explain content (two changes) and changes to engage user interest more quickly (one change). To clarify navigation in Reading the Visual we highlighted only clickable text so as not to confuse any non-linked text with linked text; numbered each page and added the number of pages to expect, to help students realise the scope of the site. At the end of each sub-section we ensured that there was a link to the next (expected) progression in the tutorial, that is, a 'What's Next' lead, that pointed the student on to the next concept. This had not been present at the conclusion of all sub-sections before the usability trials. We also renamed two of the tree diagrams within the tutorial as Summary Charts to make the meaning more intuitive and thereby aid navigation back to the main nodes or focal points. In the Family Album where some students missed analyses of images because they did not click on the verbal text below an image, an instruction was added to the home page suggesting users do this as they navigated the site, thus making the reading of the image and its relationship to each theme explicit.

To explain the content more fully, we added further explanations of difficult concepts like symbolic attribute on the relevant screen of Reading the Visual, and exemplified the concepts with more aptly chosen images. 
('Symbolic processes are about what a participant means or is' (Kress \& van Leeuwen, 1996)). We also added text to the Family Album explaining that many images can support more than one reading.

Finally, to engage student interest more rapidly, we added a new entry screen for Reading the Visual, as shown in Figure 5, better incorporating the principles of visual grammar in its design. We expected it would both engage students and foreshadow some of the ideas yet to be encountered in the site. Students are now able to manipulate the five images (using Flash) and reposition the images themselves and reflect on the results, hopefully using functional principles.

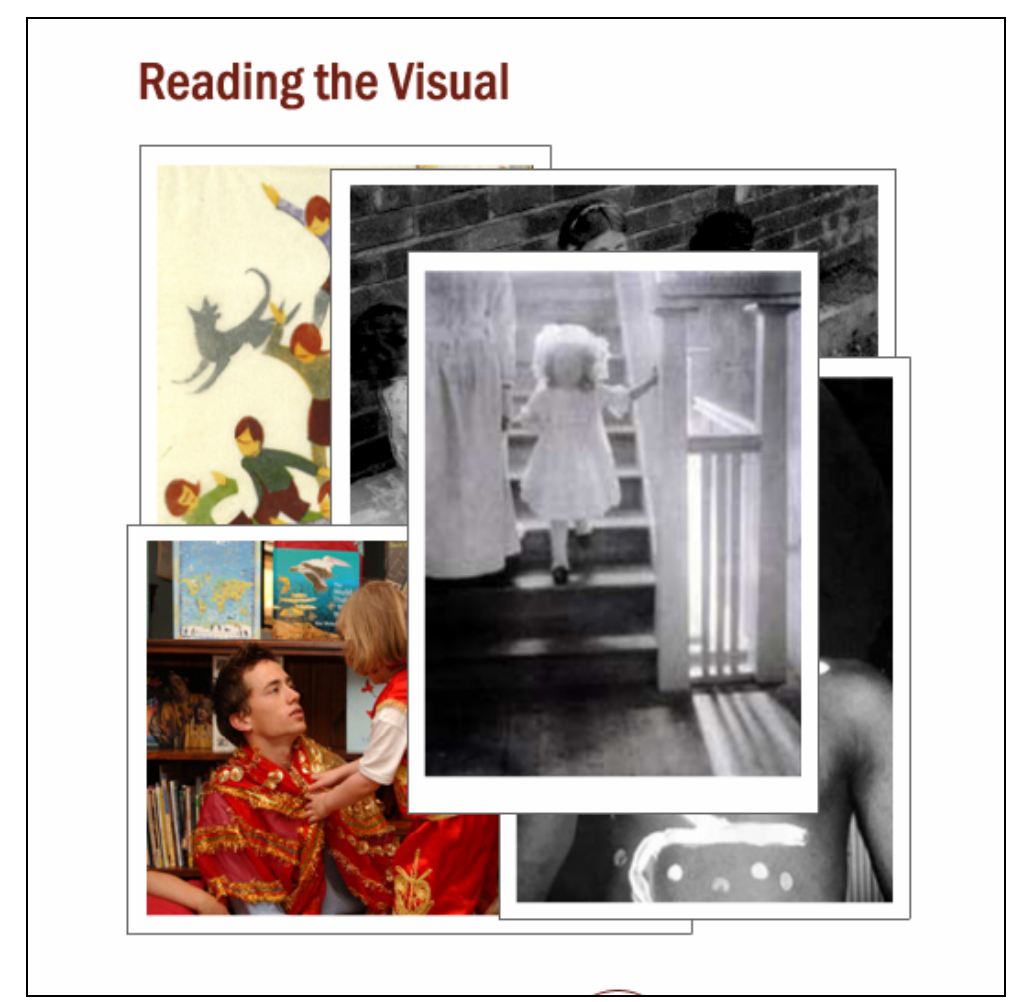

Figure 5: Entry page for Reading the Visual. Learners can manipulate the five images created in Flash, and analyse the results

At the same time, our colleagues showed interest in using these resources in other literacy courses. While the two sites were designed with a specific student cohort and context in mind, the demand for reuse of these learning 
objects (Wiley, 2002; Dalziel et al, 2005) in two other courses has emerged as an interesting new curriculum emphasis. The Reading the Visual tutorial site in particular was not conceived for a wider audience of students, but has been adapted to new contexts as the need for learning resources in the area of visual literacy education grows. The Family Album site was always in the public domain so its wider use beyond our courses is not calculable. The access logs do show, however, that it is accessed intensively towards the end of the semester in which the resources are required by students.

Further on the issue of reuse, the University lacks a central repository for resources used across different courses, so the questions of maintenance of a master copy and version control arose as issues when Reading the Visual was placed within a second WebCT course. The original version of Reading the Visual had been embedded into the navigation of the Learning Management System, so it was not easy to transfer the files. This issue was resolved when the site was revised as a resource independent of WebCT. It can now be duplicated and reused as required.

\section{The focus group}

At the focus group where we asked the interviewed students to return to review the changes to the site, students worked through each site on their own and noted their responses to changes in the sites. They then commented as a group on the modifications. In sum, they commented positively on the changes to the navigability of Reading the Visual - the bigger font, knowing how many pages to expect and the more obvious hyperlinks. They appreciated the fuller explanations of some concepts, particularly of conceptual ideational meaning. Finally, students responded to the more aesthetically pleasing entry page of Reading the Visual: it engaged their interest more readily and seemed more in keeping with the avowed purpose of the site - to embody visual language.

\section{Conclusion}

Development of visual literacy skills relies on the development of a vocabulary to articulate the meaning of images. Kress and van Leeuwen's theory provides a means of developing that vocabulary, but the theory is complex and students require support and time to build their conceptual understanding of it. Through this study we have evaluated student interactions with the learning resources built to meet that need.

In relation to our first aim, the evaluation revealed that students were indeed using the resources, and that the resources were important for scaffolding learning. As two of the resources of the unit as a whole, the 
evidence suggests that they helped cater for various learning styles and were effective in fostering students' visual literacy skills and facilitating their understanding of visual grammar. The evaluation also showed that students revisited the websites, particularly the tutorial, lingering and reflecting on the images. Students returned to the web resources for the major assignment, confirming that well designed assessments can ensure that students engage with all the resources of the unit. In a distance unit, this need to practise critical thinking and visual literacy skills is especially important.

In regard to our second aim, we found that after modifying the resources, students found them more engaging. It is therefore more likely that these resources will encourage students to revisit and reflect on the concepts of visual grammar. The students' interactions with the resources, particularly revealed through the interviews, indicated meaningful engagement with the theory and indicated that the visual resources were accessible on various levels.

In regard to methodology, the interview and talk aloud protocol sessions proved to be a very effective means of gaining user feedback. While the questionnaire could reveal, for example, that students wanted some instructions amended, they did not say which instructions. During the individual usability testing students immediately pointed out specific instructions that needed clarification. In addition, while this is only a small case study with a limited number of students in the sample, the combination of data gathering methods gives a reliable indication of how students are using the resources and whether they have any impact on learning outcomes. The talk aloud protocol and interview revealed the richest data for this.

Realising that each of the websites had become a discrete learning resource or learning object, potentially suitable for re-use and sharing, raised issues of interoperability which were resolved with minimal expenditure on the resource. Given that the websites were conceived some time ago, and the rapidity with which technology evolves, that they still remain vital educational resources, capable of use beyond their primary context, is significant. It suggests that embodying the 'grammar of the visual', the functional systemic principles of design offered by Kress and van Leeuwen, into the sites, did not compromise the educational outcomes we aimed to achieve.

In terms of investigation and future research in this area, we begin by inviting readers of this paper to reflect on how the visual has been used in this context. Is it merely illustrative or do the images and graphics have 
stories of their own to tell? What does the combination of tables, flow charts and images mixed in with the pages of text communicate to you? How does the layout, the distribution of information and the relative emphasis among various elements affect the meaning that you make of particular pages of this paper?

In conclusion, our research indicates that the resources helped our students better understand how the functional concepts of visual grammar can be used to read images of the child. This is an important step in the process of teaching and extending visual literacy in the early childhood setting. It is also important in developing students' metalanguage as it may facilitate their critical engagement with narrowly conceived notions of childhood, an important part of the critical literacy project in Early Childhood. It also serves to support the reframing of literacy to include the visual, a major change in the way we teach and learn.

\section{References}

Anstey, M. \& Bull, G. (2000). Reading the visual: Written and illustrated children's literature. Sydney: Harcourt.

Bernadini, S. (2002). Using think-aloud protocols to investigate the translation process: methodological aspects. In P. Barker \& S. Rebelsky (Eds), Proceedings of ED MEDIA 2002, World Conference on Educational Multimedia, Hypermedia and Telecommunications. Denver, Colorado, USA, 24-29 June.

Callow, J. (1999). Reading the visual: An introduction. In J. Callow (Ed), Image matters: Visual texts in the classroom (pp.1-13). Sydney: PETA.

Dalziel, J., Philip, R. \& Clare, J. (Eds) (2005). The COLIS Project: Collaborative Online Learning and Information Services. Macquarie University E-Learning Centre of Excellence (MELCOE): Sydney. http://www.colis.mq.edu.au/COLIS_CD/index.html

Dimitrova, M., Sharp, H. \& Wilson, S. (2001). Are experts able to predict learner problems during usability evaluation? Proceedings of ED MEDIA 2001, World Conference on Educational Multimedia, Hypermedia and Telecommunications. Tampere, Finland, 25-30 June.

English K-6 Modules, (1998). K-6 dot Board of Studies. K-6 Educational Resources. NSW Board of Studies. [viewed 28 Sep 2005, verified 20 May 2006] http://k6.boardofstudies.nsw.edu.au/english/index.html

Halliday, M. (1994). An introduction to functional grammar (2nd Ed.). London: Edward Arnold.

Healy, A. (2000). Visual literacy: Reading and the contemporary text environment. In R. Campbell \& D. Green (Eds), Literacies and learners: Current perspectives (pp. 155-172). Sydney: Pearson Education Australia. 
Hedberg, J., Brown, C. \& Arrighi, M. (1997). Interactive multimedia and web-based learning: Similarities and differences. In B. Khan (Ed), Web-based instruction. Englewood Cliffs, NJ: Educational Technology Publications.

Hedberg, J. \& Harper, B. (1992). Navigation options in interactive multimedia. In J. Hedberg \& J. Steele (Eds), Educational technology for the clever country: Selected papers from EdTech 92, 10-16. Canberra: AJET Publications. [verified 20 May 2006] http://www.ascilite.org.au/aset-archives/confs/edtech92/hedberg.html

Jewitt, C. \& Oyama, R. (2001). Visual meaning: A social semiotic approach. In T. van Leeuwen \& C. Jewitt (Eds), Handbook of visual analysis, (pp.134-156). London: Sage.

Kress, G. (1997). Visual and verbal modes of representation in electronically mediated communication: The potentials of new forms of text. In I. Snyder (Ed), Page to screen: Taking literacy into the electronic era. (pp.53-79). Sydney: Allen and Unwin.

Kress, G. \& van Leeuwen, T. (1990). Reading images. Geelong: Deakin University Press.

Kress, G. \& van Leeuwen, T. (1996). Reading images: The grammar of visual design. London: Routledge.

Laurillard, D. (2002). Rethinking university teaching: A conversational framework for the effective use of learning technologies. 2nd ed. London and New York: Routledge Falmer.

Neilsen, J. (2000), Why you only need to test with 5 users. Jakob Nielsen's Alertbox. [viewed 19 Sep 2005] http://www.useit.com/alertbox/20000319.html

New London Group (1996). A pedagogy of multiliteracies: Designing social futures. Harvard Educational Review, 66(1), 60-92.

Northrup, P. (2001). A framework for designing interactivity into web-based instruction. Educational Technology, 41(2), 31-39.

Sims, R. (1998). Interactivity for effective educational communication and engagement during technology based and online learning. In C. McBeath \& R. Atkinson (Eds), Proceedings of EdTech98: Planning for progress, partnership and profit. Perth: Australian Society for Educational Technology. [verified 20 May 2006] http://www.ascilite.org.au/aset-archives/confs/edtech98/pubs/articles/sims1.html

Sims, R. (2003). Promises of interactivity: Aligning learner perceptions and expectations with strategies for flexible and online learning. Distance Education, 24(1), 87-103.

State Library of New South Wales (2000). Picman collection: Documenting life in New South Wales 1870-1930. NSW State Library Picman database. [viewed 14 July 2000] http:/ / www.sl.nsw.gov.au/find/picman 
Unsworth, L. (2003). Reframing research and literacy pedagogy relating to CD narratives: Addressing radical change in digital age literature for children. Issues in Educational Research, 13(2), 55-70. [verified 20 May 2006] http://www.iier.org.au/iier13/unsworth.html

Unsworth, L., Thomas, A. \& Bush, R. (2004). The role of images and image-text relations in group Basic Skills Tests of literacy for children in the primary school years. Australian Journal of Language and Literacy, 27(1), 46-65.

van Someren, M., Barnard, Y. \& Sandberg, J. (1994). The think aloud method: A practical guide to modelling cognitive processes. London: Academic Press.

Veen, G. (2002). Resources for reading Gunther Kress' and Theo van Leeuwen's Reading images: The grammar of visual design. [viewed 30 May 2004, verified 20 May 2006] http://courses.washington.edu/englhtml/engl569/picsuup.html

Wiley, D. A. (2002). Connecting learning objects to instructional design theory: A definition, a metaphor, and a taxonomy. In D. A. Wiley (Ed.), The Instructional use of learning objects. Bloomington, USA: Agency for Instructional Technology and the Association for Educational Communications and Technology. [verified 20 May 2006] http:/ / www.reusability.org/read/

Dr Susan Roberts, Institute of Early Childhood, Macquarie University NSW 2109, Australia. Web: http://www.aces.mq.edu.au/iec/

Email: susan.roberts@mq.edu.au

Ms Robyn Philip, Macquarie E-Learning Centre of Excellence, Macquarie University NSW 2109, Australia. Web: http:/ / www.melcoe.mq.edu.au/

Email: rphilip@melcoe.mq.edu.au

Reading the Family Album website

http:/ / www.lib.mq.edu.au/readingthefamilyalbum/picman/ 